\title{
Transitive and Attitudinal Aspects in a Functional Analysis of Academic Discourse in Spanish
}

\author{
Natalia Ignatieva (1) \\ Department of Applied Linguistics, National Autonomous University of Mexico, Mexico City, Mexico \\ Email: ignatiev@unam.mx
}

How to cite this paper: Ignatieva, N. (2019). Transitive and Attitudinal Aspects in a Functional Analysis of Academic Discourse in Spanish. Open Journal of Modern Linguistics, 9, 165-178.

https://doi.org/10.4236/ojml.2019.93016

Received: March 19, 2019

Accepted: May 28, 2019

Published: May 31, 2019

Copyright $\odot 2019$ by author(s) and Scientific Research Publishing Inc. This work is licensed under the Creative Commons Attribution International License (CC BY 4.0).

http://creativecommons.org/licenses/by/4.0/

\section{(c) (i) Open Access}

\begin{abstract}
This paper presents a systemic functional analysis of three types of processes in academic texts: verbal, mental and relational. It intends to explore how certain process types in Spanish are related to the expression of evaluation in academic texts. Our study draws on Systemic Functional Linguistics and, in particular, on the Appraisal Theory, which explores evaluative aspects of the language, here we shall analyze only one of its subsystems, ATTITUDE. Our analysis is based on student texts collected at the Faculty of Arts, belonging to two disciplines: literature and history, but to only one genre: question-answer. The preliminary results show certain differences between the two corpora: in the literature texts clauses with appraisal prevail and JUDGMENT is the preferred means of expressing ATTITUDE, while the history texts prefer clauses without appraisal and APPRECIATION prevails among the subtypes of ATTITUDE.
\end{abstract}

\section{Keywords}

Academic Writing, Text, Process, Evaluation, Interpersonal, Appraisal, Appreciation, Judgement

\section{Introduction}

This paper presents a systemic functional (SF) analysis of three types of clauses: verbal, mental and relational in academic texts, from the ideational and interpersonal perspectives. This work forms part of the on-going research study developed at the National Autonomous University of Mexico (UNAM) which, in its turn, is included in the SAL (Systemics across Languages) project in its Latin American version. The goal of the SAL project is to analyze verbal processes 
("verbs of saying") as one of the most important types within the SF verbal typology and their use in different types of discourse across registers and genres. As an international project, the SAL also aims at involving as many different languages as possible in this study. We had already participated in the SAL project before with the study of verbal processes in academic texts in Spanish within the systemic functional framework and had carried out a lexicogrammatical analysis of the verbal clauses (Ignatieva, 2011; Ignatieva \& Rodríguez-Vergara, 2015).

The present project extends this research to other types of processes. We begin our analysis with processes because, according to the SF framework, the construction of a sentence as a meaning-making unit starts with choosing a process type which describes the world of experience and at the same time organizes the participants of the situation described. In other words, we are carrying out a transitivity analysis of academic texts.

Besides, we decided to combine transitivity analysis with the Appraisal Theory perspective, i.e. we want to observe how students express their attitude in academic writing and what linguistic resources they choose for this purpose. Finally, we are interested in the interaction of transitive and attitudinal aspects of academic writing, that is, we want to see what processes students choose in their texts and if these process types are related to the expression of appraisal in the clauses that contain them. We are planning to analyze all types of clauses (verbal, mental, relational, material, behavioral and existential) throughout disciplines (literature, history and geography) and genres (question-answer, essay, review, report and article). We shall be using student texts from the CLAE corpus (Corpus of Academic Language in Spanish (CLAE, 2009)): the product of one of our previous studies (Ignatieva \& Colombi, 2014), as well as other student texts recollected at the UNAM.

So our main goal is to examine the relation between certain process types and the expression of evaluation in the clauses containing them. This relation between ideational and interpersonal meanings and, as a consequence, between the systems of TRANSITIVITY and APPRAISAL, was mentioned by Martin and White (2005) in their analysis of different types of discourse. In accordance with this, our study has to do with two levels of analysis: lexicogrammatical and discourse semantic, and two systems: TRANSITIVITY and APPRAISAL. Although there are studies which connect some process types with different kinds of evaluation (Hyland, 1999; Chen, 2007; Lavid, 2008; etc.) they do not treat this problem from the angle adopted in this work, besides most of these studies take English as the basis for their exploration.

In this paper we are going to analyze only a small part of our project, i.e. three types of processes: verbal, mental and relational ones, we chose mental and relational processes for their proximity to verbal ones in the famous "wheel" from the cover of the second edition of Halliday's Introduction to Functional Grammar (Halliday, 1994), where verbal processes are situated between mental and relational ones (see Figure 1). 


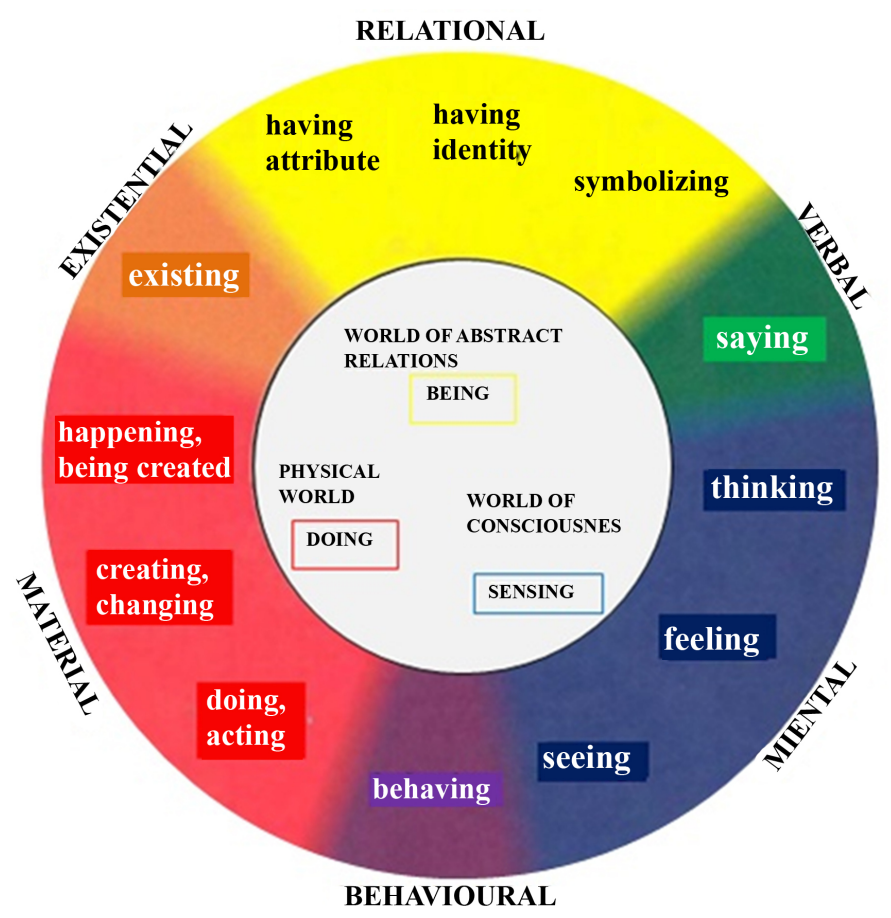

Figure 1. Transitivity “wheel” (adapted from Halliday (1994)).

Here we want to explore academic texts of only one genre (question-answer) but two disciplines (literature and history). The starting point will be a TRANSITIVITY analysis of these texts followed by an APPRAISAL analysis trying to reveal the interaction of these two systems. Our goal is to explore how ideational (experiential) and interpersonal meanings unfold in student writing and how writers use different options for encoding semantic categories of ATTITUDE.

\section{Systemic Functional Perspectives on TRANSITIVITY and ATTITUDE}

Our study draws on Systemic Functional Linguistics (SFL) created by M. A. K. Halliday $(1976,1985,1994)$ and developed by other exponents of this theory (Martin, 1985, 1992; Matthiessen, 1995; Thompson, 1996; etc.). The theory presents a holistic model of language and its social context which conceives language as a meaning construing resource.

The SFL model describes and explains language from multiple and complimentary perspectives to provide a global vision of the linguistic phenomena. One of the fundamental perspectives is functional. Halliday (2004) considers language as a system of meanings conditioned by its functions, he labels them metafunctions, i.e. the most abstract and general functions that are common to all human languages. These are three: the ideational metafunction which reflects world reality and our experiences in the world, the interpersonal metafunction which has to do with the participants of interactions and their opinions, feelings, etc. and the textual metafunction which organizes the text. These metafunctions, which act and coexist in the language simultaneously, permit us to express three 
types of meaning: ideational, interpersonal and textual.

Ideational meanings and, in particular, experiential ones, are those that a writer or speaker manipulates to codify his experiences in the exterior and interior world. They are materialized in the clause via a linguistic system of TRANSITIVITY that concerns different combinations of participants organized around a process in the clause. It refers to "a way of representing patterns of experience (...) of imposing order on the endless variation and flow of events" (Halliday, 1994: p. 106). In other words, it is the organization of the sentence which construes the world of experience into a set of process types. Halliday divides processes into six types: "material", "mental", "relational", "verbal", "behavioral" and "existential".

Textual meanings are occupied with the information flow and they organize and distribute ideational and interpersonal meanings into a coherent text.

Interpersonal meanings have to do with social relations, i.e. how people interact, how they express and interchange their opinions. Their basic systems are MODALITY which defines the type of exchange (giving and demanding information or giving and demanding services) and EVALUATION (Martin \& White, 2005). Thus, the metafunctional approach to analysis is important as this approach can facilitate our recognizing the ways in which "interpersonal meanings relate to ideational choices in the discourse" (Hood, 2010). So, our main interest concerns the interaction between the ideational and interpersonal meanings realized through TRANSITIVITY and APPRAISAL systems, respectively.

The APPRAISAL system is a theoretical perspective for examining evaluative aspects of language within the SFL framework. Created within the Sydney School of SFL, this theory presents one of the systems of textuality (Martin \& White, 2005), which models linguistic resources, giving cohesion to the text from the point of view of values, attitudes and the author's stance. Thus, the Appraisal makes it evident how an affective-evaluative language contributes to textual coherence on the discursive semantic level.

The APPRAISAL system is divided into three subsystems: ATTITUDE, ENGAGEMENT and GRADUATION; here we shall analyze only one subsystem, ATTITUDE. As a construct, ATTITUDE models linguistic resources which are grouped under the term of evaluation in some other theories (e.g. Thompson \& Hunston, 2000). The subsystem of ATTITUDE includes linguistic options to express emotions (affect), to appraise things and abstract entities using aesthetic criteria (appreciation) and to evaluate persons on the basis of ethical criteria (judgement). In accordance with that, the ATTITUDE subsystem is also divided into three regions: AFFECT, APPRECIATION and JUDGEMENT (Martin \& White, 2005: pp. 35-36). To sum up, the model of APPRAISAL provides "a basis for a theoretically informed analysis of the interpersonal meanings" construed in the student texts (Hood, 2010).

It is worth noting that most work on appraisal has been done analyzing English while little research has been conducted in Spanish (but we can mention Kaplan, 2007; Navarro, 2014; Moss \& Mizuno, 2015, etc.). We believe, however, 
that the Appraisal Theory in its basic terms has a universal potential, i.e. it can be applied to Spanish or any other language. Therefore, there is a need for more applications of this theory in order to prove its total or partial applicability and see if there is any specificity for particular languages.

\section{Construing Evaluation}

In order to register all the cases of expressing attitude we tried to single out linguistic categories that would help us to describe not only evaluation in the text but also the interaction of ideational and interpersonal meanings. As it was already noticed within the SFL, evaluation can be expressed in the text deploying a wide range of linguistic means. According to Thompson and Hunston (2000), each kind of evaluation draws differently on resources of grammar, therefore, there are different ways of encoding evaluation in the clause. Thus, processes can realize evaluation intrinsically, i.e. an attitudinal meaning can be infused into the process itself, e.g.:

1) Cardenio ama a Luscinda. (L8)

"Cardenio loves Luscinda"

where attitude is expressed as an affective process amar (love). Although the experiential meaning (as a piece of information conveyed by the author) may dominate in this context, its interpersonal meaning (as denoting feelings) still implies affect with positive polarity. The processes in which its ideational meaning is infused with attitudinal meaning usually belong to the group of mental processes, Hunston (1995) calls them "verbs of attribution", another example would be:

2) Lo que le interesa es señalar los hechos concretos. (H9)

"What interests him is to note concrete facts"

In 2) a mental process interesar (interest) expresses affect with positive polarity denoting some sort of inclination. Other groups of processes can also encode evaluation, e.g. some verbal processes which take Target as the second participant in the act of communication (the first being Sayer), e.g.:

3) Don Quijote la justifica (a Dulcinea). (L1)

"Don Quijote justifies her"

In 3) we have a case of judgement with positive polarity because this statement implies that Don Quijote says positive things about Dulcinea in order to improve her image. Verbal processes like justificar represent a closed set; they are called "processes of verbal impact" by Matthiessen (1995: p. 285) and include verbs like acusar (accuse), felicitar (congratulate), elogiar (praise), etc., with no verbalization at all either as Verbiage or locution (Caffarel, 2006: p. 90), i.e. they incorporate "the message" in the verb meaning.

Another way of realizing evaluation is by means of a nominal group (NG), e.g.:

4) ... y le cuenta su tristeza. (L12)

"and she tells him (about) her sadness"

In 4) the verbal process contar (tell) introduces a noun group su tristeza, 
which is analyzed as an example of affect with negative polarity. Both nouns (as in 4)) and adjectives (as in 5)) can encode attitude within a noun group, in the latter case an adjective functions as an epithet (inteligente $y$ libre) modifying a noun (elección). 5) is an example of judgement with a positive value introduced by the relational process ser (be):

5) El amor y el casamiento entre dos jóvenes debe ser una elección inteligente $y$ libre. (L15)

"Love and marriage between two young people must be an intelligent and free election"

Another form of including evaluation in the clause is with the help of an attribute, e.g.:

6) Para Bloch, la observación es importante. (H1)

"For Bloch, observation is important"

7) Cardenio se vuelve salvaje... (L 8)

"Cardenio becomes savage"

In 6) we can observe a relational process ser (be) that is linked with an attribute importante (important) to be analyzed as a case of appreciation with positive polarity while in 7) another relational process volverse together with an attribute salvaje encodes judgement with a negative value. Evaluation can also be realized by a clause, usually it is a projected clause with a verbal 8) or mental 9) process in the projecting clause, e.g.:

8) Él afirma que nadie tiene porqué hablar mal de élla. (L13)

"He affirms that nobody has to speak badly of her"

9) Entonces debe entenderse que la realidad histórica... es digna de ser tomada como objeto de estudio. (H4)

"So it should be understood that a historic reality ... is worthy to be taken as an object of study"

Example 8) presents a case of judgement with positive polarity expressed by a clause, that is projected by a verbal process afirmar (affirm). In 9) the projected clause encodes appreciation with positive polarity and the projecting process in this case is mental. Finally, evaluation can be realized by an adjunct, e.g.:

10) Don Quijote... se sabe como buen caballero (L7)

"Don Quijote recognizes himself as a good gentleman"

11) El Quijote con mucho enfado responde saber quién es él en persona (L10).

"Quijote responds very angrily that he knows who he is in person"

In 10) judgement with positive polarity is associated with a mental process saber, while in 11) the verbal process is accompanied by an adjunct to express affect with negative polarity.

To sum up, a process, a NG, an attribute, a clause and an adjunct were taken as operative categories which embody linguistic realization of evaluation.

\section{Corpus and Method}

The data for the analyses are drawn from the $C L A E$ corpus, i.e. student texts 
collected at the Faculty of Philosophy and Arts of the National Autonomous University of Mexico, belonging to two disciplines: literature (15 texts) and history (10 texts), but to only one genre: question-answer, which is an assignment that students have to do in class as part of their term examination. In its initial form the texts were handwritten, then they were transcribed and digitalized by the researcher.

The method used in this study combined three complementary types of analysis: quantitative, qualitative and contrastive. We quantified the number of clauses and the number of each process type in the two corpora: literature texts and history texts. Then we distinguished between the clauses that express appraisal and those that are neutral while the clauses with appraisal were classified in three groups according to the division of the attitude system into the subtypes: affect, appreciation and judgement. Finally, we compared the results of our two corpora and drew conclusions.

In order to code appraisal we tried using the same criteria that had already been applied to English corpora (Hood, 2010). For deciding between the categories of our analysis we basically used conceptual criteria; we also relied on a paraphrase test and deferred to authorities checking similar examples in the textbooks (O’Donnell, Zappavigna, \& Whitelaw, 2008). For difficult cases, we organized discussions within the project meetings where we tried to arrive at solutions that the majority of the research participants would support.

\section{Data and Initial Analysis}

In accordance with our method, we began with counting the number of words and clauses in our corpora and registered the frequency of verbal, mental and relational processes in these clauses, the results are presented in tabular form below.

We can appreciate from Table 1 that the processes analyzed in the literature corpus (LC) amount to 255: 82 of them are relational, 104 are verbal and 69 are mental while in the history corpus (HC) the number of the processes is 261: 114 are relational, 93 are verbal and 54 are mental.

Figure 2 presents the total frequency of each process type in our two corpora where in the LC verbal processes clearly take the lead and amount to $41 \%$, relational processes are in second place while in the $\mathrm{HC}$ is vice versa, relational processes are in the first place followed by verbal processes. Mental processes are less frequent in both corpora and take the third place.

Table 1. Process frequency in our corpora.

\begin{tabular}{cccccccccc}
\hline Texts & Words & Clauses & Processes & Relational & \multicolumn{2}{c}{ Verbal } & \multicolumn{2}{c}{ Mental } \\
\hline & $\mathrm{N}$ & $\mathrm{N}$ & $\mathrm{N}$ & $\mathrm{N}$ & $\%$ & $\mathrm{~N}$ & $\%$ & $\mathrm{~N}$ & $\%$ \\
\hline Literature & 3937 & 563 & 255 & 82 & $32 \%$ & 104 & $41 \%$ & 69 & $27 \%$ \\
History & 5071 & 547 & 261 & 114 & $44 \%$ & 93 & $36 \%$ & 54 & $21 \%$ \\
\hline
\end{tabular}




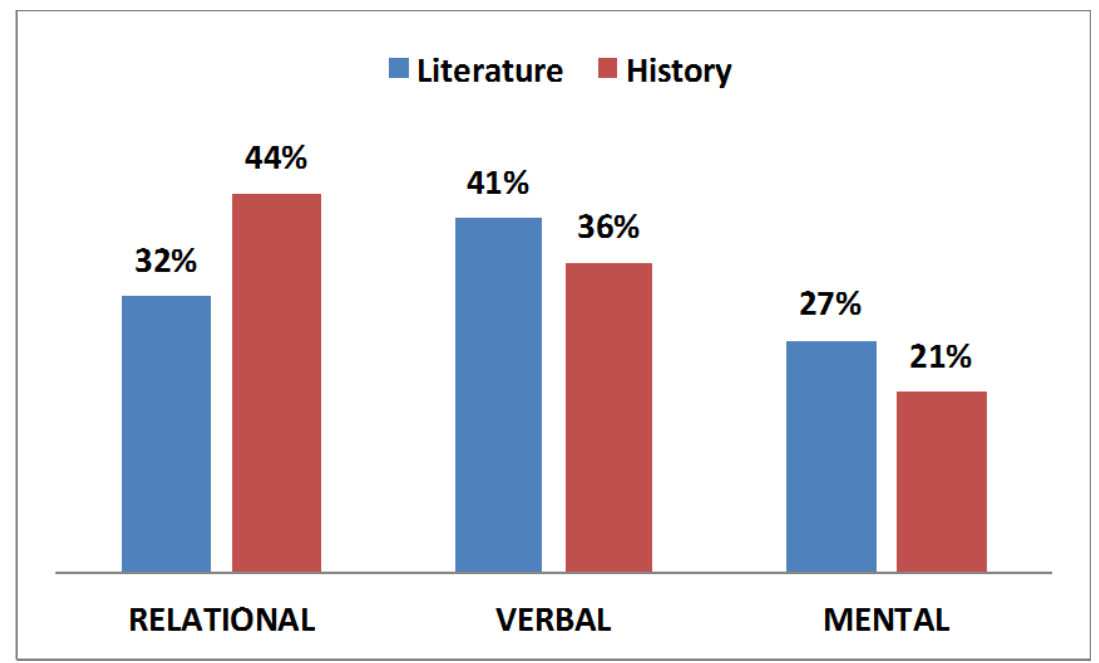

Figure 2. Total frequency of each process type in our corpora.

The next step is to detect and analyze all the clauses that express attitude into two groups: those that express evaluative meanings and those that do not. Table 2 makes the results of this analysis available.

As can be appreciated from Table 2, clauses that encode some type of evaluation prevail in the LC where they almost double those that are neutral. The HC displays quite a different picture where most clauses lack evaluation and only a quarter of them contain evaluative elements.

Next, we divided clauses containing evaluation into positive and negative according to their polarity, the resulting data are given in Table 3.

As shown in Table 3, positive evaluation dominates in both corpora: $67 \%$ in the LC and $78 \%$ in the HC, we can also see that a numeric value of negative evaluation in literature texts is higher than that of history texts.

Now we are going to observe which of the three types of processes under analysis is more associated with evaluation.

Table 4 makes it evident that in the LC 61\% among the relational clauses, $62 \%$ among the verbal ones and 78\% among the mental are associated with some sort of appraisal while these numbers for the HC are respectively: $25 \%, 24 \%$ and $26 \%$, respectively.

The total results are also shown in Figure 3 where there is a visual representation of the three types of processes associated or not with evaluation. The processes are given in percentages in relation to all the clauses within each corpus. Thus, it becomes evident that in the LC, verbal processes take the lead $(25 \%)$ as far as an association with appraisal is concerned; they are followed by mental processes $(21 \%)$ and relational ones $(20 \%)$. As for the HC, its numbers are quite smaller: $11 \%$ for relational processes (first place), $8 \%$ for the verbal and $5 \%$ for the mental (Table 5).

Figure 4 shows how three domains of ATTITUDE are distributed between the clauses which express evaluation in both corpora. It can be derived from Figure 4 that in the LC JUDGEMENT surpasses the other two domains (AFFECT and 
Table 2. Frequency of clauses with and without evaluation.

\begin{tabular}{cccccc}
\hline Texts & Processes & \multicolumn{2}{c}{ Processes with evaluation } & \multicolumn{2}{c}{ Processes without evaluation } \\
\hline & & $\mathrm{N}$ & $\%$ & $\mathrm{~N}$ & $\%$ \\
\hline Literature & 255 & 168 & $66 \%$ & 87 & $34 \%$ \\
History & 261 & 65 & $25 \%$ & 196 & $75 \%$ \\
\hline
\end{tabular}

Table 3. Frequency of clauses with positive and negative evaluation.

\begin{tabular}{ccccc}
\hline Texts & Positive & \multicolumn{2}{c}{ Negative } \\
\hline & $\mathrm{N}$ & $\%$ & $\mathrm{~N}$ & $\%$ \\
\hline Literature & 113 & $67 \%$ & 55 & $33 \%$ \\
History & 51 & $78 \%$ & 14 & $22 \%$ \\
\hline
\end{tabular}

Table 4. Frequency of clauses with and without evaluation within each process type.

\begin{tabular}{|c|c|c|c|c|c|c|c|c|c|c|c|c|}
\hline \multirow[t]{2}{*}{ Texts } & \multicolumn{2}{|c|}{$\begin{array}{c}\text { Relational } \\
\text { with } \\
\text { evaluation }\end{array}$} & \multicolumn{2}{|c|}{$\begin{array}{c}\text { Relational } \\
\text { without } \\
\text { evaluation }\end{array}$} & \multicolumn{2}{|c|}{$\begin{array}{l}\text { Verbal with } \\
\text { evaluation }\end{array}$} & \multicolumn{2}{|c|}{$\begin{array}{c}\text { Verbal } \\
\text { without } \\
\text { evaluation }\end{array}$} & \multicolumn{2}{|c|}{$\begin{array}{c}\text { Mental with } \\
\text { evaluation }\end{array}$} & \multicolumn{2}{|c|}{$\begin{array}{c}\text { Mental } \\
\text { without } \\
\text { evaluation }\end{array}$} \\
\hline & $\mathrm{N}$ & $\%$ & $\mathrm{~N}$ & $\%$ & $\mathrm{~N}$ & $\%$ & $\mathrm{~N}$ & $\%$ & $\mathrm{~N}$ & $\%$ & $\mathrm{~N}$ & $\%$ \\
\hline Literature & 50 & $61 \%$ & 32 & $39 \%$ & 64 & $62 \%$ & 40 & $38 \%$ & 54 & $78 \%$ & 15 & $22 \%$ \\
\hline History & 29 & $25 \%$ & 85 & $75 \%$ & 22 & $24 \%$ & 71 & $76 \%$ & 14 & $26 \%$ & 40 & $74 \%$ \\
\hline
\end{tabular}

Table 5. Frequency of clauses with and without evaluation within each corpus.

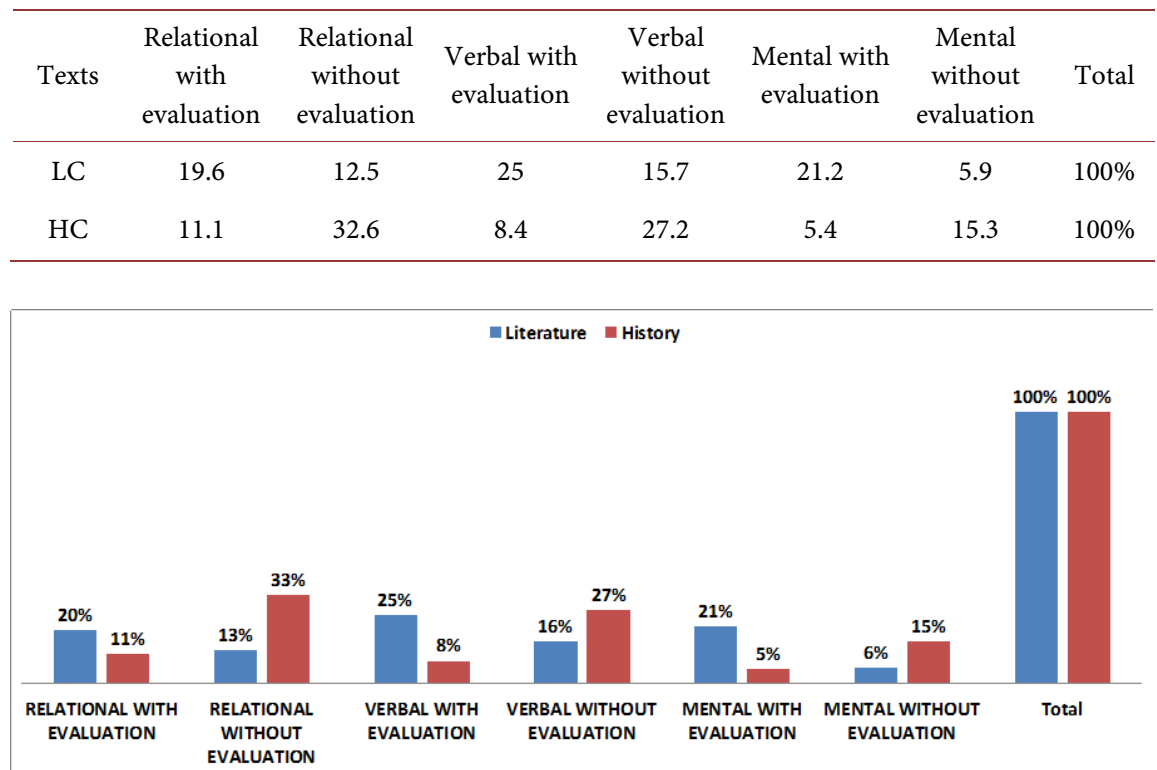

Figure 3. Three types of processes in relation to evaluation.

APPRECIATION) in the three types of clauses under analysis: among the relational clauses $46 \%$ express JUDGEMENT, $42 \%$ APPRECIATION and 12\% AFFECT; in the group of verbal clauses we have $61 \%$ of JUDGEMENT, $23 \%$ of APPRECIATION and $16 \%$ of AFFECT; finally, among the mental clauses we 
have $39 \%$ of JUDGEMENT, $31 \%$ of APPRECIATION and 30\% of AFFECT. As a result, verbal clauses with JUDGEMENT occupy the first place in the literature texts.

In the HC the picture is totally different, APPRECIATION stands out as overwhelmingly dominant in the three types of clauses: $83 \%$ among the relational clauses versus $14 \%$ of JUDGEMENT and 3\% of AFFECT; 77\% among the verbal clauses versus $23 \%$ of JUDGEMENT and $0 \%$ of AFFECT; $79 \%$ among the mental clauses versus $7 \%$ of JUDGEMENT and $14 \%$ of AFFECT. Consequently, relational clauses with APPRECIATION take first place in the HC.

Finally, we registered ATTITUDE realization in our corpus in terms of the linguistic categories mentioned above. The results can be observed in Figure 5. An attribute turns out to be the most typical expression of ATTITUDE in the student texts of both corpora, although much more so for the $\mathrm{HC}$ as compared to the LC. It is followed by a process but only for the LC; in the HC, on the contrary, a process seems to be scarcely used at all. A projected clause and a nominal group show similar values in both corpora while an adjunct results to be the least typical resource in the LC, but more widely used in the HC. So, the differences between the two corpora in the linguistic realization of ATTITUDE concern mainly two categories: a process and an adjunct.

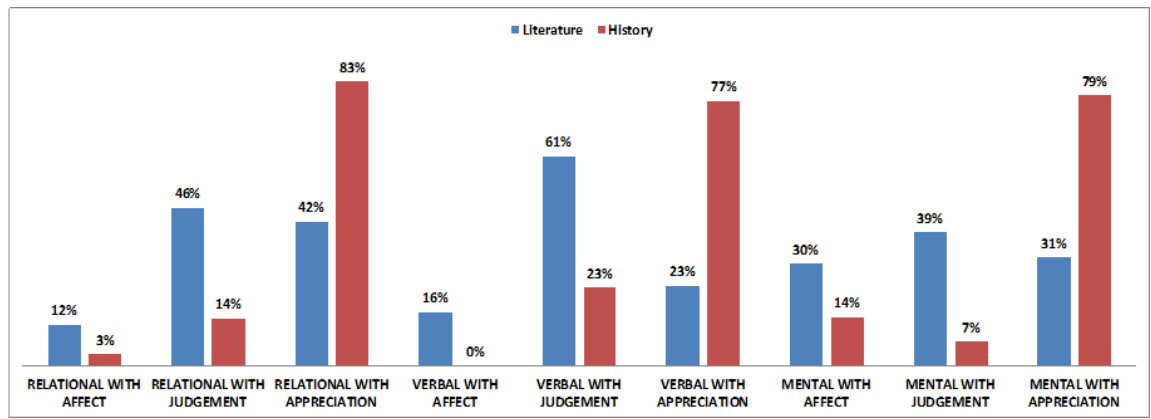

Figure 4. Three domains of ATTITUDE as associated with the tree types of processes.

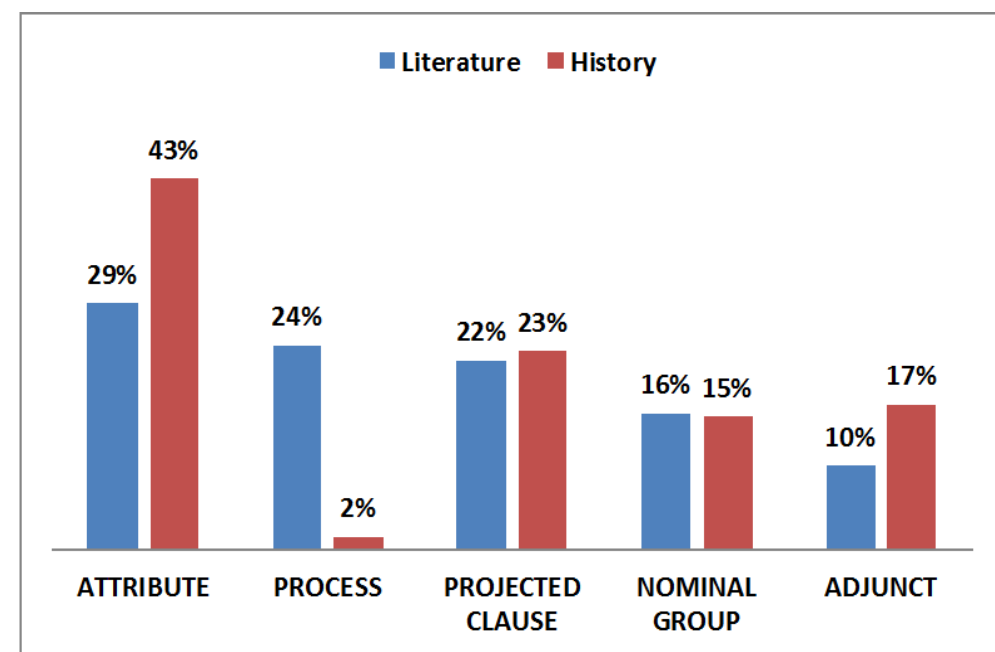

Figure 5. Linguistic realization of attitude in our corpus. 


\section{Discussion and Conclusion}

In this paper, we tried to examine the relation between the types of processes and the expression of evaluation at the semantic discursive level. We wanted to explore how choices that students make from the system of transitivity interact with the choices they make from the appraisal system. Transitivity analysis carried out in this research showed differences in the student corpora: in the LC verbal clauses prevail over relational ones which are in second place and in the HC relational processes dominate verbal ones while mental processes are the least frequent of the three types under study in both corpora.

Analyzing the APPRAISAL system we could observe still more differences between the two corpora. Thus, in the LC, clauses with evaluation prove to be dominant; they almost double the number of the clauses without evaluation. In the $\mathrm{HC}$ it is quite the reverse, most clauses (75\%) are neutral and do not contain evaluative elements. This difference seems to be striking if we take into consideration that both literature and history texts belong to the same genre (question-answer).

We can also notice that expressing appraisal students are more inclined toward positive evaluation as compared with negative: in the LC the former surpasses the latter more than twice; in the HC, more than thrice, which may be the result of the fact that students' critical capacity of analysis is not yet fully developed. This tendency toward positive evaluation seems to be one of the very few points where the two corpora are similar.

As for the type of process associated more with evaluative aspects, verbal processes outnumber the mental and relational clauses and result in first place in the LC while in the HC the first place belongs to relational processes. This is not surprising taking into account that, in general, verbal processes are most frequent in the LC and relational processes prevail in the HC. This finding looks logical if we consider the semantics of verbal processes which serve to express opinions, attitudes and feelings, among other things and therefore, are essential in the LC. In the same way, the meaning of relational processes which express a state of things explains their wide use in history texts (Moss \& Chamorro Miranda, 2011).

A question of the three domains of the ATTITUDE system is closely connected with the type of process discussed above. Thus, JUDGEMENT (linked to verbal processes) is the preferred means of expressing APPRAISAL in the LC, as compared with AFFECT and APPRECIATION. In contrast, history texts realize APPRAISAL basically through APPRECIATION (linked to relational processes). It may be deduced that literature students are more inclined to judge persons, than to appreciate things or express emotions, and consequently "student voice" tends to sound judgemental. On the other hand, it may also depend on the topic of their writing since in the texts analyzed they are asked to give their opinions on some literary characters. History students, on the contrary, tend to evaluate facts, events and happenings and considerably less, historic figures. 
The exploration of a linguistic realization of attitude revealed that an attribute turned out to be the most frequent means of appraisal expression in both corpora, which could be expected taking into account the fact that an attribute is characteristically associated more with relational processes which have a high frequency in both literature and history texts.

The second place in the LC is occupied by a process itself. As we have mentioned earlier, an attitudinal meaning can be encoded in the process itself, this is characteristic of verbal and mental processes. On the other hand, verbal and mental processes have a projecting capacity and projection often acts to construe interpersonal meaning (Thompson, 2004) and functions to encode the writer's stance or attitude (Forey, 2008). As expected, then, the second most frequent means of expressing attitude in the $\mathrm{HC}$, and the third in the LC, is a clause, most often it is a projected clause. This is in accordance with some other studies that suggest that projecting clauses function as "an interpersonal lens through which the projected clause is interpreted" (Coffin \& Hewings, 2004: p. 162).

So our analysis made it evident that there are more differences than similarities between student literature and history texts although both belong to the same genre. Thus, a question-answer in literature is a text with a predominance of verbal processes, an abundance of evaluative elements (mostly positive) where judgement prevails; besides, an attribute and a process are the preferred means of expressing attitude. In the area of history a question-answer is a text where relational processes dominate; the style is mostly neutral as the number of evaluative elements is not high, and when they do occur their purpose is usually to express appreciation with the help of an attribute or projected clause.

So we obtained an interesting picture of the interaction of TRANSITIVITY and APPRAISAL systems registering frequent links between certain process types and the expression of attitude. Consequently, we observed a complex interplay of the lexicogrammatical and semantic discursive aspects of academic texts which finally points to a close relation between the ideational and interpersonal functions of the language.

Besides, this study may contribute to our better understanding of genre characteristics in student texts and at the same time show the significance of their variation across disciplines. The results of our analysis may find a wide application in the teaching of academic writing, especially in university settings. A functional approach to writing instruction may help students to construe a text on a semantic basis (beginning with types of processes) and to exploit evaluative elements in order to express their opinions and take a stance on the topic of writing.

The tendencies that we discovered in our exploration of student writing from the functional perspective need to be confirmed by exploring more corpora and comparing the data from different genres and disciplines.

\section{Acknowledgements}

The project Verbal typology and attitude evaluation in the academic writing of 
the humanities: A systemic functional study is carried out thanks to a grant from the National Autonomous University of Mexico.

\section{Conflicts of Interest}

The author declares no conflicts of interest regarding the publication of this paper.

\section{References}

Caffarel, A. (2006). A Systemic Functional Grammar of French: From Grammar to Discourse. London: Continuum.

Chen, L. (2007). Analysing Attitude: Positive Verbal Process Sub-Functions and Media Bias. RASK, International Journal of Language and Communication, 25, 25-55.

CLAE (2009). El lenguaje académico en español. Análisis binacional de textos en las humanidades. http://www.lenguajeacademico.info

Coffin, C., \& Hewings, A. (2004). IELTS Preparation for Tertiary Writing: Distinctive Interpersonal and Textual Strategies. In L. Ravelli, \& R. Ellis (Eds.), Academic Writing in Context: Social-Functional Perspectives on Theory and Practice (pp. 153-171). London: Continuum.

Forey, G. (2008). Projecting Clauses: Interpersonal Realization of Control and Power in Workplace Texts. In G. Forey, \& G. Thompson (Eds.), Text Type and Texture (pp. 151-172). London: Equinox.

Halliday, M. A. K. (1976). System and Function in Language. London: Oxford University Press.

Halliday, M. A. K. (1985). Spoken and Written Language. Geelong: Deakin University Press.

Halliday, M. A. K. (1994/2004). An Introduction to Functional Grammar. London: Arnold.

Hood, S. (2010). Appraising Research: Evaluation in Academic Writing. London: Pal Grave Macmillan. https://doi.org/10.1057/9780230274662

Hunston, S. (1995). A Corpus Study of Some English Verbs of Attribution. Functions of Language, 2, 133-158. https://doi.org/10.1075/fol.2.2.02hun

Hyland, K. (1999). Academic Attribution: Citation and the Construction of Disciple Nary Knowledge. Applied Linguistics, 20, 341-367. https://doi.org/10.1093/applin/20.3.341

Ignatieva, N. (2011). Verbal Processes in Student Academic Writing in Spanish from a Systemic Functional Perspective. Lenguaje, 39, 447-467.

Ignatieva, N., \& Colombi, M. C. (2014). CLAE: Corpus del lenguaje académico en español de México y los Estados Unidos: Un análisis sistémico funcional. México: UNAM.

Ignatieva, N., \& Rodríguez-Vergara, D. (2015). Verbal Processes in Academic Language in Spanish: Exploring Discourse Genres within the Systemic Functional Framework. Functional Linguistics, 2, 1-10. https://doi.org/10.1186/s40554-015-0014-9

Kaplan, N. (2007). La teoría de la valoración: Un desarrollo de los estudios sobre la evaluación en el lenguaje. In A. Bolívar (Ed.), Análisis del discurso. Por qué y para qué (pp. 45-66). Caracas: Universidad Central.

Lavid, J. (2008). The Grammar of Emotion in English and Spanish: A Systemic-Functional Approach. In C. Jones, \& E. Ventola (Eds.), From Language to Multi Modality: New Developments in the Study of Ideational Meaning (pp. 67-85). London: Equinox. 
Martin, J. (1985). Factual Writing: Exploring and Challenging Social Reality. Oxford: Oxford University Press.

Martin, J. (1992). English Text. Philadelphia, PA: John Benjamins. https://doi.org/10.1075/z.59

Martin, J., \& White, P. R. (2005). The Language of Evaluation. New York: Palgrave Macmillan. https://doi.org/10.1057/9780230511910

Matthiessen, C. M. I. M. (1995). Lexicogrammatical Cartography: English Systems. Tokyo: International Language Sciences.

Moss, G., \& Chamorro Miranda, D. (2011). La pedagogía de la simplificación: La en señanza de historia por medio de pista y pesca. In (Re)Construcción: Discurso, identidad y nación en los manuales escolares de historia y y de ciencias sociales (pp. 269-320). Chile: Editorial Cuarto Propio.

Moss, G., \& Mizuno, G. (2015). Las voces del texto. In N. Barletta Manjarrés, \& D. Chamorro Miranda (Eds.), El texto escolar y el aprendizaje (pp. 89-117, Se gunda edición). Colombia: Universidad del Norte.

Navarro, F. (2014). Gradación y compromiso en escritura académica estudiantil de humanidades. Análisis contrastivo desde la Teoría de la Valoración. Estudios de Lingüística Aplicada, 60, 9-33.

O’Donnell, M., Zappavigna, M., \& Whitelaw, C. A (2008). Survey of Process Type Classification over Difficult Cases. In C. Jones, \& E. Ventola (Eds.), From Language to Multimodality: New Developments in the Study of Ideational Meaning (pp. 47-64). London: Equinox.

Thompson, G. (1996/2004). Introducing Functional Grammar. London: Arnold.

Thompson, G., \& Hunston, S. (2000). Evaluation: An Introduction. In G. Thompson, \& S. Hunston (Eds.), Evaluation in Text: Authorial Stance and the Construction of Discourse (pp. 1-27). Oxford: Oxford University Press. 